\title{
Francisco López de Gómara y Hernán Cortés: nuevos testimonios de la relación del cronista con los marqueses del Valle de Oaxaca/
}

Francisco López de Gómara and Hernán Cortés: New testimonies on the relationship between the Chronicler and the Marquesses of Oaxaca Valley ${ }^{1}$

\section{M. ${ }^{a}$ del Carmen Martínez Martínez}

Universidad de Valladolid

Las declaraciones del cronista Francisco López de Gómara en dos pleitos permiten esclarecer algunos aspectos de su relación con Hernán Cortés y su heredero Martín Cortés. Estos testimonios tuvieron lugar en 1549, cuando ya se ocupaba de escribir sobre el conquistador, y en 1551, poco antes de la publicación de la Historia de las Indias y conquista de México. Los vínculos que revela Gómara con el entorno de Cortés en España son claves para entender las fuentes de su obra e iluminan algunos años de su vida.

Palabras Clave: Francisco López de Gómara; Hernán Cortés; Martín Cortés; Marquesado del Valle de

Oaxaca; Cronistas de Indias; Siglo XVI; Nueva España; Historiografía.

The chronicler Francisco López de Gómara shows on two lawsuits some aspects of his own relationship between Hernán Cortés and Hernán Cortés heir, Martín Cortés. These statements were made in 1549 when he had already been entrusted with the writing about the conqueror, as well as in 1551, little time before his Historia de las Indias y conquista de México was published. Gómara s link with Cortés in Spain are highly relevant to understand the sources of his writings and these statements give a very important information on some period of his life.

KeYwords: Francisco López de Gómara; Hernan Cortés; Martín Cortés; Marqueses of Oaxaca Valley;

Chroniclers of The Indies; 16th Century; New Spain; Historiography.

1 La investigación se ha desarrollado dentro del proyecto "La tradición Clásica y Humanística en España y América, ss. XVI-XVIII", de la Subdirección General de Proyectos de Investigación (ref. FFI22009-13049-C04-01). 
Francisco López de Gómara fue uno de los grandes historiadores del reinado de Carlos V, uno de los más originales e interesantes, como ha puesto de manifiesto Nora Edith Jiménez en la que hasta ahora es su biografía más completa. ${ }^{2}$ Más allá del escenario americano considerado en $\mathrm{La}$ Historia de las Indias y conquista de México, ${ }^{3}$ publicada en Zaragoza en 1552, Gómara escribió sobre la política mediterránea del emperador en las Guerras de mar de nuestro tiempo ${ }^{4}$ y se detuvo en algunos de sus protagonistas en Los corsarios Barbarroja. ${ }^{5}$ Su gran capacidad de síntesis quedó demostrada en los Annales del emperador Carlos Quinto, ${ }^{6}$ en los que recogió por años los acontecimientos más relevantes de su siglo desde el nacimiento de don Carlos hasta 1556. Pese a su empeño no hay constancia de que lograse el ambicionado nombramiento de cronista, ni la edición de las tres últimas obras mencionadas, hecho que no impidió que sus escritos fueran ampliamente utilizados, incluso por sus críticos y detractores.

La biografía de López de Gómara se ha ido perfilando lentamente. Marcos Jiménez de la Espada publicó el texto que contiene un retrato escrito del clérigo. ${ }^{7}$ Roger Bigelow Merriman se percató de que los Annales contenían notas autobiográficas, como la de su nacimiento en febrero de 1511 en la villa soriana de Gómara. Robert Earl Lewis dio a conocer su testamento, que contenía referencias a su entorno familiar, y apuntó que su fallecimiento se habría producido en la misma jornada que lo dispuso, el 2 de diciembre de 1559 , o poco después, pues en su opinión lo redactó in articulo mortis. ${ }^{8}$ Con certeza sabemos que ya no vivía en abril de 1563 , como se comprueba en las actuaciones de sus testamentarios. ${ }^{9}$

La historiografía tradicional sobre López de Gómara recreaba algunas circunstancias de su vida a partir de meras conjeturas, asumidas sin apenas

2 Nora Edith Jiménez, Francisco López de Gómara.

3 Francisco López de Gómara, La istoria de las Yndias.

4 Francisco López de Gómara, Guerras de mar. Como han demostrado los editores, fray Prudencio de Sandoval utilizó esta obra, sin dejar constancia alguna, en su Historia del emperador Carlos $V$.

5 Francisco López de Gómara, Los corsarios Barbarroja.

6 Francisco López de Gómara, Annales del emperador. El texto, que no vio la luz en vida del autor, fue editado en 1912 por Roger Bigelow Merriman, Annals of the Emperor.

7 Marcos Jiménez de la Espada, De un curioso percance, pp. 9-10.

8 Robert Earl Lewis, The humanistic. Sobre la última voluntad del cronista Lewis: "El testamento de Francisco López de Gómara".

9 Archivo Histórico Nacional (en adelante AHN), Madrid, Órdenes Militares, Archivo Histórico de Toledo, 42.070. Poder de Fernán González de Almarza, chantre de Soria, Pedro Ruiz y Brígida López a favor de Juan Ruiz para cobrar las cantidades debidas a Francisco López, clérigo difunto, Gómara, 28 de abril de 1563. 
discusión, entre ellas, la más repetida, la condición de capellán y biógrafo asalariado de Hernán Cortés. Los trabajos de Juan Miralles y Nora Edith Jiméne $\mathrm{z}^{10}$ cuestionan ya este aserto, a partir del análisis de la obra y de la biografía de Gómara. También se ha dado por supuesto el trato de López de Gómara con el conquistador, aunque sólo está probada documentalmente la relación con su hijo Martín. Este artículo trata de la relación del cronista con los marqueses del Valle, a través de testimonios inéditos, y enriquece sus perfiles biográficos.

\section{López de Gómara, testigo jurado}

Se conservan pocos documentos escritos o firmados por Gómara. A los reseñados por Robert Earl Lewis ${ }^{11}$ y José Pinilla ${ }^{12}$ se ha sumado la publicación de una interesante carta del clérigo soriano al obispo de Arras. ${ }^{13} \mathrm{~A}$ ellos añadimos las dos declaraciones inéditas, firmadas de su puño y letra, que ahora damos a conocer, y que se conservan en sendos pleitos seguidos ante el más alto tribunal de justicia de Castilla, la Real Chancillería de Valladolid. Además, en otro litigio visto en el Consejo Real, hemos encontrado una carta de obligación de Martín Cortés en la que Francisco López de Gómara aparece como testigo. ${ }^{14}$

El motivo de los pleitos seguidos en la Chancillería vallisoletana fue la dote de María Cortés. Hernán Cortés había concertado en 1545 con Pedro Álvarez Osorio, marqués de Astorga, el matrimonio de sus hijos María Cortés y Álvaro Pérez Osorio. Se acordó una dote de 100.000 ducados pagaderos en cinco anualidades y Cortés se comprometió a traer a España a su hija antes de finales de 1546. En septiembre de 1547, no sin dificultades y acuciado por el marqués de Astorga, había entregado los pri-

10 Jiménez, Francisco López de Gómara. p. 102, resalta y desarrolla la hipótesis que planteó Miralles en el estudio preliminar a Francisco López de Gómara, Historia de la conquista. Véase también Juan Miralles, Hernán Cortés, pp. 612-613 y Juan Miralles Ostos, “Gómara”, pp. 165-175, trabajo en el que coteja argumentos con el propósito de esclarecer si fue capellán de Cortés, concluyendo lo mucho que desconocía de la vida del conquistador.

11 Lewis, "El testamento", pp. 75-76.

12 José Pinilla, "López de Gómara", pp. 390-392.

13 Real Biblioteca (en adelante RB), Madrid, Fondo Granvela, II/2252, fol. 304r. Carta de Francisco López de Gómara al obispo de Arras, Zaragoza, 20 de noviembre de 1552. Se publicó en Avisos, VIII, 32, Madrid, enero-marzo de 2003.

14 Archivo General de Simancas (en adelante AGS), Valladolid, Consejo Real, 386-7. Pleito entre Juan de Lezcano y Martín Cortés, marqués del Valle, sobre deudas y ejecución de bienes, Valladolid, 1553. 
meros 20.000 ducados en efectivo, joyas y asumiendo deudas del marqués. Cortés murió meses antes de la llegada de María y don Pedro optó por casar a su primogénito con una hija del duque de Alba. Roto el compromiso, el conde de Aguilar, como curador de Martín Cortés, y el duque de Medina Sidonia, que lo era de María Cortés, se querellaron contra el marqués de Astorga por los 20.000 ducados recibidos y que no quiso devolver. ${ }^{15}$

Años más tarde, Martín Cortés, ya marqués del Valle, fue demandado por los hermanos Aranda, comerciantes de Valladolid, quienes le reclamaron una deuda contraída por su padre. ${ }^{16}$ En septiembre de 1545 Hernán Cortés había asumido como propio el débito que con ellos tenía el marqués de Astorga, como parte del pago de la dote de su hija María. ${ }^{17}$

En ambos pleitos el clérigo Francisco López de Gómara dio muestras de su relación con la casa de los marqueses del Valle y del conocimiento que tenía del concierto de la boda de María Cortés. En enero de 1549 fue presentado como testigo para responder a veinte de las treinta preguntas del interrogatorio redactado por los letrados del conde de Aguilar y del duque de Medina Sidonia en el litigio con el marqués de Astorga. Años después, en agosto de 1551, declaró en el pleito de los Aranda con Martín Cortés, aclarando que los vasallos y bienes del marqués del Valle estaban en la Nueva España.

Entre enero y marzo de 1549 los albaceas de Hernán Cortés realizaron probanzas en Valladolid, Logroño y Sevilla para presentar en la causa que seguían contra el marqués de Astorga. En Valladolid declararon Juan Altamirano, Alonso de San Clemente, Pedro de Ahumada, fray Diego Altamirano, Francisco de Persoa, el doctor Francisco de Espinosa "el viejo", el licenciado Hernando de Chaves y Francisco López de Gómara, presentado como "clérigo presbítero de la diócesis de Osma, estante en esta

15 Archivo de la Real Chancillería de Valladolid (en adelante ARChV), Pleitos Civiles, Masas, Fenecidos, 3351-2. Pleito entre el conde de Aguilar, curador de Martín Cortés, marqués del Valle, y Juan Alonso de Guzmán, duque de Medina Sidonia, curador de María Cortés, con el marqués de Astorga reclamando, como albaceas de Hernán Cortés, 20.000 ducados que Pedro Álvarez Osorio había recibido como parte de la dote asignada a María Cortés en su matrimonio con Álvaro Pérez Osorio, 1548-1551.

16 Ibidem, Pleitos Civiles, Moreno, Fenecidos, 2802-2. Demanda de Juan de Astorga, en nombre de Antonio de Aranda y sus hermanos, mercaderes, vecinos de Valladolid, a Martín Cortés, marqués del Valle, a sus hermanas María, Catalina y Juana, como herederos de Hernán Cortés, y a Pedro Ramírez de Arellano, conde de Aguilar, como su curador, Valladolid, 9 de junio de 1551.

17 Ibidem. Obligación de Hernán Cortés con Antonio, Diego y Cristóbal de Aranda, vecinos de Valladolid, por 786.405 maravedís, importe de las mercancías que el marqués de Astorga sacó de su tienda, Valladolid, 15 de septiembre de 1545. 
corte", prestando todos ellos juramento antes de responder a las preguntas del escribano. López de Gómara lo hizo el 26 de enero, poniendo su mano derecha sobre el pecho y jurando por las órdenes de san Pedro y san Pablo que había recibido. De ello fueron testigos Pedro de Ahumada, camarero del marqués, y Alonso de San Clemente, alcaide de Nalda, una de las villas del conde de Aguilar. El clérigo, a su vez, actuó como testigo de los juramentos de estos últimos.

Los testigos declararon individualmente y mientras que algunos fueron examinados por todas las preguntas del interrogatorio, otros, entre ellos Gómara, sólo respondieron a aquellas para las que habían sido presentados. Además de las específicas de cada probanza, el escribano que recibía el testimonio hacía las conocidas como preguntas generales, denominadas así porque se formulaban a todos los testigos antes de su declaración. Entre ellas se le preguntó a Gómara por su edad y si era pariente o enemigo de los litigantes, si le iba interés en el pleito, le habían prometido alguna cosa o intimidado por decir lo contrario a la verdad y si quería que alguna de las partes venciese en la causa. ${ }^{18}$ López de Gómara declaró ser de edad de "treinta e ocho años poco más o menos", lo que cuadra perfectamente con la referida noticia de que nació en 1511. Analizaremos el resto de sus respuestas más adelante, antes de ello es interesante recoger algunas declaraciones que demuestran su interés y reconocida curiosidad.

\section{Gómara y el camino de las Indias}

Aunque Gómara nunca viajó al Nuevo Mundo su curiosidad lo llevó a indagar y a preguntar a gentes relacionadas de una u otra manera con aquel escenario, sin desdeñar la mera conversación, siempre enriquecedora, con quienes habían realizado aquella navegación. De su método de trabajo dio cuenta en sus escritos y también al responder a las preguntas del interrogatorio que trataban sobre las condiciones de la travesía y las distancias que había que salvar hasta alcanzar las Indias. Los relatos de pasajeros, hombres de mar, pilotos y maestres debieron de deleitar a Gómara a quien sorprendía, como escribió en una ocasión, que el sutil arte de navegar estuviese en manos de "gente grosera y que no sabe leer". ${ }^{19}$

18 Dichas preguntas se formulaban para saber el juez que entendía en la causa las circunstancias que concurrían en el testigo. Gabriel de Monterroso y Alvarado, Pratica civil y criminal, pp. 17v-18.

19 López de Gómara, Guerras de mar, p. 58. 
Gómara llevaba ya años trabajando en La Historia de las Indias cuando declaró en 1549. Respondió con soltura, haciendo gala de su amplia experiencia en tomar distancias, al señalar que sobre el trayecto entre Sanlúcar y Veracruz: "lo que sabe es que ende la Nueva España a Sanlúcar hay dos mil leguas de navegación poco más o menos, según este testigo muchas veces ha tomado la medida con compás del dicho camino en la carta del navegar". ${ }^{20}$ Buena muestra de aquella habilidad quedó plasmada a la hora de escribir sobre el sitio de las Indias y remitir al lector a la representación cartográfica que incluía en su obra, ${ }^{21}$ demostrando en otras ocasiones su gran capacidad integradora y de relación. Así, en las Guerras de mar, al tratar sobre las navegaciones, hizo mención al tiempo empleado por el conquistador en la travesía durante su primer regreso a España: "Hernando Cortés, en 36 días de navegación, vino de la Veracruz a Sanlúcar de Barrameda, que son más de 1.800 leguas". ${ }^{22}$ Bernal Díaz del Castillo, que en este caso no pudo tomar el dato de las inéditas Guerras de mar de Gómara, señaló cuarenta y uno. ${ }^{23}$

Tradicionalmente los conocimientos técnicos de Gómara se han relacionado con el manejo de la obra de Pedro Mexía, cosmógrafo de la Casa de la Contratación, ${ }^{24}$ y aunque aclaró que la cuenta en leguas y grados "va según las cartas de los cosmógrafos del Rey", ${ }^{25}$ las vivencias propias le permitieron dejar testimonio de las distancias de algunos trayec-

20 ARChV, Pleitos Civiles, Masas, Fenecidos, 3351-2. Probanza de los testamentarios de Hernán Cortés, marqués del Valle, en el pleito con el marqués de Astorga. Declaración de Francisco López de Gómara, Valladolid, 26 enero de 1549. En las citas se moderniza la ortografía y se reconstruye entre corchetes el texto que no es posible leer por la pérdida del soporte escriturario así como las letras omitidas por el escribano que dificultarían la lectura.

21 Francisco López de Gómara, Historia general, pp. 22-27. En la obra de Jiménez (Francisco López de Gómara), entre las pp. 303-305, sin numerar, se reproducen las representaciones cartográficas de la edición de Zaragoza de 1552. Los mapas también aparecen en la edición de Zaragoza: a costa de Miguel Çapila, 1553 (1552), como se comprueba en el ejemplar de la Real Biblioteca, Madrid (BR. V/1150) y en el que una nota manuscrita en la primera hoja en blanco aclaró "Primera y segunda parte de la Historia general de las Yndias con la conquista de México / por / Francisco López de Gómara / editio 1. / Prohibita a supremo Indiarum senatu / 1552 et 1553 ". Otro ejemplar de esta edición con ambos grabados puede consultarse en la Biblioteca Histórica de Santa Cruz de la Universidad de Valladolid (U/Bc I y R 323).

22 López de Gómara, Guerras de mar, p. 58. AGS, Consejo Real, 333-14. Por la declaración de Pedro de Ahumada en el pleito por el embargo de 800 ducados que pidió el licenciado Núñez en los bienes del marqués del Valle sabemos que Cortés partió de Veracruz el 5 de enero de 1540 y desembarcó en Sanlúcar el 6 de abril; por lo tanto el comentario de Gómara se refiere al viaje de 1528.

23 Bernal Díaz del Castillo, Historia verdadera, p. 363.

24 López de Gómara, Guerras de mar, p. 142.

25 López de Gómara, Historia general, XII, p. 27. 
$\operatorname{tos}^{26} \mathrm{y}$ afirmar "que toda mar es peligrosa por habello e[x]p[er]imentado en otras mares que este testigo ha navegado e ansimesmo oyó decir este testigo [a] algunas presonas ( $\mathrm{sic}$ ), que no se acuerda de sus nombres, como en el dicho tiempo andaban corsarios por aquella mar y camino". ${ }^{27}$ Conociendo su gran curiosidad y deseo de saber debieron ser muchos sus informantes.

Con los datos facilitados por quienes habían realizado la travesía atlántica recreó la ruta pues "hablando e [pre]guntando a muchos que han an[dado] este viaje e navegación ha en[ten]dido cómo al ir de España a la [Nue]va España no es muy peligro[so des]de Sevilla a Canaria pero que, a la venida, desde la Veracruz hasta La Habana, es muy mala e peligrosa de pasar la canal de Bahama y otros muchos pasos malos hay en el dicho camino e muy largos". ${ }^{28}$ De forma muy parecida se expresó por escrito al tratar el camino de las Indias en su obra. ${ }^{29}$

\section{Gómara conoce a Hernán Cortés: "Ende que vino la primera vez de la Nueva España"}

La historiografía sitúa el inicio de la relación de Gómara y Cortés a raíz del segundo viaje del conquistador a España (1540-1547), sin más precisión que el escenario en el que tuvo lugar el encuentro. Roger Bigelow Merriman advirtió sobre la presencia del cronista en la campaña de Argel (1541), en la que también participó Hernán Cortés, y señaló que allí se conocerían. ${ }^{30}$ Así se ha repetido en los estudios de Ramón Iglesia, ${ }^{31}$ Jorge Gurría Lacroix, ${ }^{32}$ Simón Valcárcel, ${ }^{33}$ José Luis Martínez ${ }^{34}$ y más reciente-

26 López de Gómara, Guerras de mar, p. 58. "Él ha venido de Génova a Palamós con una carabela en menos de cincuenta horas, que son más de 300 leguas".

27 ARChV, Pleitos Civiles, Masas, Fenecidos, 3351-2. Declaración de López de Gómara, Valladolid, 26 enero de 1549.

28 Ibidem.

29 López de Gómara, Historia general, CCXXI, p. 315: "Desvíanse a la venida de la derrota que llevaron, trescientas leguas, y aun por ventura cuatrocientas. Hacen tan diferente camino a la vuelta por seguridad y presteza. Segura navegación es toda, por ser la mar larga, aunque pocos navegan que no cuenten de tormentas; lo peor de pasar a la ida es el golfo de las Yeguas, entre Canaria y España, y a la venida, la canal de Bahama, que es junto a la Florida".

30 Roger Bigelow Merriman, Introducción a Francisco López de Gómara: Annales, p. X.

31 Ramón Iglesia, Cronistas e historiadores, p. 98.

32 Jorge Gurría Lacroix, Prólogo a Francisco López de Gómara: Historia General, p. XII.

33 Simón Valcárcel Martínez, "Una aproximación”, p. 9.

34 José Luis Martínez, Hernán Cortés, p. 736. 
mente en las bien documentadas publicaciones de Nora Edith Jiménez, tanto en su monografía sobre el cronista como en el estudio en el que dio a conocer el compendio del texto de las Guerras de mar. ${ }^{35}$ Sin embargo, la declaración de Gómara en 1549 demuestra que ya lo conocía desde su primer viaje a España (1528).

La primera de las treinta preguntas del interrogatorio preparado por los letrados del conde de Aguilar —el doctor Burgos de Paz y el licenciado Puebla - para examinar a los testigos presentados en el pleito con el marqués de Astorga, buscaba esclarecer el conocimiento y relación que esos testigos tenían con los litigantes. En este sentido se les preguntó si conocían al conde de Aguilar, a Martín Cortés, marqués del Valle, y a su hermana María Cortés, al marqués de Astorga, don Pedro Álvarez Osorio, y a su primogénito, don Álvaro Pérez Osorio, y si habían conocido al difunto Hernán Cortés, marqués del Valle. La sorprendente respuesta de Gómara, que por su interés reproducimos íntegra, fue la siguiente:

\begin{abstract}
A la primera pregunta del dicho interrogatorio dijo este testigo que conoce a todos los contenidos en la dicha pregunta e a cada uno de ellos, e[x]ce[p]to a la dicha doña María Cortés. Al conde de Agilar (sic) de más de veinte años a esta parte e al dicho marqués don Martín Cortés que puede haber que le conoce seiete (sic) ocho años poco más o menos; e a la dicha doña María Cortés que no la conoce; e al dicho marqués don Fernando [Cor]tés que le conoce de dicinueve o ve[inte] años a esta parte, ende que vino [la] primera vez de la Nueva Espa[ña]; e ansimesmo dijo que conoce [al] marqués don Álvar (sic) Pérez Oso[rio] de dicinueve años a esta parte [poco] más o menos; e al dicho don Álvar [Pérez] Osorio de obra de cinco años a esta parte poco más o menos; a los cuales que dicho tiene que conoce e a cada uno de ellos dijo que los conoce de vista e habla e conversación que desde el dicho tiempo acá con ellos e con cada uno de ellos ha tenido e tiene..$^{36}$
\end{abstract}

López de Gómara pronunció las palabras citadas bajo juramento y las ratificó tras leerle el escribano su declaración. Después tomó la pluma y, con su inconfundible letra pulida y menuda, firmó al pie de sus respuestas. Pese a que la pieza del pleito en la que se encuentra la probanza está deteriorada en el margen inferior derecho, lo que obliga a restituir algunas letras, es posible leer con total claridad que Gómara declara que conoce a Cortés "ende que vino [la] primera vez de la Nueva Espa[ña]", nota 418 .

35 Jiménez, Francisco López de Gómara, pp. 95-98. López de Gómara, Guerras de mar, p. 14,

36 ARChV, Pleitos Civiles, Masas, Fenecidos, 3351-2. Probanza de los testamentarios de Hernán Cortés. Declaración de López de Gómara, Valladolid, 26 enero de 1549. 
momento que corroboró al puntualizar el tiempo transcurrido, diecinueve o veinte años, lo que nos llevaría a establecer el primer encuentro en 1529 o 1530.

Sus palabras introducen un cambio radical y notorio en su relación con Cortés al adelantar en el tiempo su encuentro. Este pudo influir en su "fascinación" por ese conquistador y el Nuevo Mundo, por ser sus cosas tan diferentes a las conocidas, como expuso en la dedicatoria al emperador en La Historia de las Indias. ${ }^{37}$

Sin duda, a partir de su declaración podemos hacer otra lectura de los comentarios que dedicó en su obra a los dos viajes de Cortés a la Península. Sobre el primero señaló que "Llegó a España en fin del año de 1528, estando la corte en Toledo. Hinchó todo el reino de su nombre y llegada, y todos le querían ver". ${ }^{38}$ Ahora sabemos que él fue uno de los que tuvieron la oportunidad de hacerlo. El joven Francisco López de Gómara sentiría la curiosidad de la que siempre hizo gala y podría saciarla siendo testigo directo de la estancia de Cortés y sus acompañantes en la corte.

Las palabras de Gómara dan un nuevo valor a algunas de las descripciones que hace del primer regreso de Cortés, como cuando escribe sobre su acompañamiento, con la ágil prosa del que recrea una imagen de la que ha sido testigo: "Trajo ocho volteadores de palo, doce jugadores de pelota, y ciertos indios e indias muy blancos, y otros enanos, y otros contrechos. Y sin todo esto traía para ver, tigres, alcatraces, un aiotochtli, otro tlacuaci, animal que ensena o embolsa sus hijos para comer; ... y para dar, gran suma de mantas de pluma y pelo, ventalles, rodelas, plumajes, espejos de piedra, y cosas asî" ${ }^{39}$ De la habilidad de aquellos naturales y de su presencia en la corte, con la imagen en la retina, también escribió al ocuparse de las distracciones del tlatoani azteca: "A España vinieron después algunos con Cortés que jugaban así de pies, y muchos los vieron en corte. También hacían matachines; ca se subían tres hombres uno sobre otro de pies llanos en los hombros, y el postrero hacía maravillas. ${ }^{40}$ Algunas de las escenas descritas por Gómara de los jugadores de pies y de pelota, y que tanto fascinaron a los que las contemplaron, fueron dibujadas por Cristoph Weiditz

37 López de Gómara, Historia general, p. 7. Los textos del conquistador y el cronista han sido analizados por Glen Carman, Rhetorical conquests.

38 Francisco López de Gómara, Historia de la conquista de México, CXCII, p. 272.

39 Ibidem.

40 Ibidem. LXVIII, p. 103. 
durante su estancia en España en 1529, quien también realizó en la ocasión un retrato de Hernán Cortés. ${ }^{41}$

La declaración de López de Gómara sobre el momento en el que conoció al conquistador es de gran importancia porque lo convierte en testigo del éxito de Cortés en su primer regreso, imagen bien distinta a la que acompañó al marqués durante su segunda estancia en España, de la que también sería testigo tras el regreso de Argel.

Nos preguntamos si la figura, las hazañas de Cortés, las novedades y maravillas del Nuevo Mundo deslumbraron a Gómara desde la primera vez que lo vio. Sea como fuere, en el prólogo de la Crónica de los Barbarroja que en 1545 dedicó al marqués de Astorga rezuma aquella fascinación al insistir en varias ocasiones que escribía sobre "las maravillosas cosas de Cortés", además de asegurar con rotundidad "yo a lo menos nunca me arrepentiré de haber escrito de Cortés, ni aun de Barbarroja tampoco". ${ }^{42}$

\section{Escenarios compartidos: Toledo, Zaragoza, Barcelona}

Cuestión que no desvela Gómara es el lugar en el que conoció al conquistador. Para establecerlo es necesario seguir el itinerario de Cortés en España. Francisco Núñez, su procurador, señala que llegó en mayo de 1528 y que, en los primeros días de junio, se reunieron en la Puebla de Guadalupe para luego dirigirse juntos a Toledo. ${ }^{43}$ Fue en esta ciudad donde Bernal Díaz del Castillo situó el encuentro del conquistador con el emperador, aunque otros autores se inclinan por Monzón. ${ }^{44}$

41 El Códice de los trajes. Trachtenbuch / 2v. Reproducción facsímil del manuscrito original conservado en el Museo Nacional Germánico de Nuremberg, Sig. Hs. 22474.

42 López de Gómara, Los corsarios Barbarroja, pp. 15-16. Curiosamente, la obra no se identifica con claridad en los registros conocidos de la biblioteca de la casa de Astorga, aunque en ellos si se consignó la existencia de la "Primera parte de las [sic] ystoria general de las Yndias con todo el descubrimiento y conquista de México y de la Nueva España" y de la "Segunda parte de esta ystoria de México de la conquista della, entranbas en un cuerpo". Antonio M. Cátedra, Nobleza, pp. 352 y 453. Sobre la presencia de ambos protagonistas en la obra de Gómara véase Miguel Ángel de Bunes Ibarra, “Cortés”, pp. 901-911 y Jiménez, Francisco López de Gómara, pp. 213-215.

43 ARChV, Pleitos Civiles, Zarandona y Balboa, Olvidados, 145-2, fol. 184r/v. Poder de Hernán Cortés al licenciado Núñez, relator del Consejo de Su Majestad, Puebla de Guadalupe, 5 de junio de 1528 .

44 Amada López de Meneses, "El primer regreso", pp. 69-91, p. 72. Demetrio Ramos: Hernán Cortés, pp. 241-242, también señaló que el escenario del encuentro del conquistador y don Carlos fue Monzón, donde se celebraban Cortes, considerando que Bernal Díaz mezcló los acontecimientos al situar la entrevista en Toledo. 
Gómara era clérigo del obispado de Osma, y si aceptamos, como ha señalado Nora Edith Jiménez, ${ }^{45}$ que se mueve en la corte en relación muy probablemente con García de Loaisa, presidente del Consejo de Indias y obispo de Osma, pudo llegar a Toledo al tiempo o poco después que el rey, quien entró en la ciudad a mediados de octubre. ${ }^{46}$ Debió de ser entonces, a finales de 1528 o a comienzos del año siguiente, cuando Gómara tuvo la oportunidad de conocer a Cortés es decir, veinte años "poco más o menos" antes de su declaración en enero de 1549.

Por Gómara conocemos que Cortés entregó al emperador "los materiales que traía escritos, y le acompañó hasta Zaragoza, que se iba a embarcar a Italia por coronarse" ${ }^{47}$ Don Carlos llegó a la capital aragonesa el 23 de marzo y permaneció en ella hasta el 19 de abril de $1529 .{ }^{48}$ Si seguimos al cronista se deduce que fue el escenario en el que coincidió por última vez con el emperador antes de que éste abandonase España. Desde Zaragoza, tras acompañar a don Carlos, Hernán Cortés se dirigió a la corte para encaminarse luego, a finales de marzo, a la villa de Béjar para casarse con doña Juana de Zúñiga. ${ }^{49}$ Tras la boda se trasladaron a Mérida desde donde, a comienzos de julio, con gran prisa, se puso en camino para alcanzar de nuevo a la comitiva regia que ya se encontraba en Barcelona..$^{50}$ Nada dicen sobre este viaje Gómara ni Bernal, a pesar de que sabemos que el primero se encontraba allí. ${ }^{51}$

Fue mucho lo que Cortés logró en aquella jornada, entre otras la expedición de la merced de los vasallos ${ }^{52}$ y del título de marqués del Valle de Oaxaca, el nombramiento de capitán general de la Nueva España y, además, en palabras del conquistador, la destitución de la primera Audiencia de México. Cortés, informado de los insultos e injusticias de los miembros

45 La hipótesis en Jiménez, Francisco López de Gómara, pp. 43-51.

46 Manuel Foronda y Aguilera, Estancias, p. 316.

47 López de Gómara, Historia de la conquista, CXCII, p. 272.

48 Foronda, Estancias, p. 322-323.

49 Así lo señaló desde Toledo Diego de Ordaz en una carta a su sobrino Francisco Verdugo: "El gobernador i nuevo marqués del Valle partió desta corte el segundo día de Pasqua Florida, que se contaron XXIX de março. Váse a Béjar a casarse, i de ally a ver a su madre, i a Sevilla a se enbarcar". El texto de la carta en Enrique Otte: "Nueve cartas", pp. 102-130, p. 105.

50 De aquel viaje a Barcelona y de las gestiones realizadas informó Cortés a su primo Francisco Núñez en una carta que fechó en Barcelona el 30 de julio de 1529. Hernán Cortés, Cartas y memoriales, p. 136.

51 López de Gómara, Guerras de mar, p. 128.

52 López de Gómara (Historia de la conquista, CXCIII, pp. 272-273), sitúa la concesión del marquesado el 6 de julio de 1528, aunque el documento fue expedido en 1529. Martínez, Documentos cortesianos, vol. 3, pp. 53-54. 
de ese Tribunal por cartas del dominico fray Pedro de Contreras, del obispo de México y de otras personas que no concreta, partió de Mérida por la posta para alcanzar al emperador en Barcelona. Aquella jornada fue mencionada por Diego de Ordaz $^{53}$ en varias cartas y recordada por Cortés en 1545 en los tribunales al afirmar que el emperador ordenó al secretario Francisco de los Cobos y a algunos consejeros que lo acompañaban que:

vista la información queste que depone dio por las dichas cartas, de los insultos cometidos por los dichos jueces en la dicha Nueva España, por mandado de Su Majestad y con su acuerdo, mandaron dar provisión real para que los dichos jueces fuesen removidos e puestos otros e les tomasen residencia; la cual dicha provisión real este que depone trajo e presentó en el Consejo de las Indias en Madrid y porque este que depone tenía los navíos a punto para se partir, y a su mujer había dejado en Mérida, se partió y dejó poder al dicho licenciado Núñez para que hiciese cierta probanza que los señores del Consejo de Indias mandaron que se hiciese y esta probanza será la quel dicho licenciado pudo hacer. ${ }^{54}$

Sin embargo, a quien recordó Gómara con motivo de la destitución de la primera Audiencia fue al licenciado Francisco Núñez, primo y procurador de Cortés, atribuyéndole un protagonismo que el marqués del Valle ya le había quitado a su pariente ante la Justicia. Al respecto escribió: "no solo se probó su injusticia y pasión en México [la de Nuño de Guzmán y sus oidores] más aun en la corte, y en muchos lugares de España lo probó el licenciado Francisco Núñez con personas que de allá entonces vinieron". ${ }^{55}$

\section{López de Gómara, un clérigo entre nobles}

Gómara afirmó en 1549 que conocía al conde de Aguilar "de más de veinte años", por lo tanto antes que a Cortés. La proximidad de las villas y lugares del Señorío de Cameros y Marquesado de Aguilar a la diócesis de Osma, de la que dijimos era clérigo Gómara, bien pudieron facilitar aquel trato. Pedro Ramírez de Arellano, conde de Aguilar, era hermano de doña

53 Enrique Otte: "Nueve cartas...", pp. 112 y 116. Diego de Ordaz escribió sobre la presencia de Cortés en Barcelona en dos cartas escritas en Toledo a finales de agosto de 1529: "El marqués del Valle estando en Mérida con su muger, ... tubo nuevas y supo lo que en la Nueva España pasava ... y luego partió por la posta, y pasó por esta corte y fue a Barçelona”.

54 AGS, Consejo Real, 588-7. Juramento de calumnia de Hernán Cortés, marqués del Valle, y respuesta a las posiciones que le puso el licenciado Francisco Núñez en el pleito por el embargo de 800 ducados, Valladolid, 27 de abril de 1545.

55 López de Gómara: Historia de la conquista, CXCV, p. 274. 
Juana de Zúñiga, con quien se había concertado el matrimonio del conquistador. ${ }^{56}$ De la relación de Cortés con la nobleza titulada escribió Bernal Díaz del Castillo cuando recordó que lo recibieron en la corte el duque de Béjar, tío de doña Juana, el conde de Aguilar y otros grandes señores que le hicieron mucha honra. ${ }^{57}$

Gómara, al escribir sobre cómo se casó Cortés, señaló el aprecio del emperador por los condes de Aguilar, don Carlos y don Alonso de Arellano, y que Juana de Zúñiga era "hermosa mujer", ${ }^{58}$ demostrando su conocimiento de dicha familia. Desconocemos si la pudo tratar antes de casarse con Cortés, aunque si podemos afirmar, haciéndonos eco de sus palabras, que: "él no vio casar ni velar a los dichos marqueses, más de que siempre este testigo vía hablar al dicho marqués del Valle de la dicha doña Juana de Zúñiga, llamándola [e n]ombrándola mujer". Así se lo había oído decir a muchas personas y tuvo la ocasión de comprobarlo en su última voluntad, pues afirma que "ha leído este testigo el dicho testa[men]to, donde la nombra por su mujer [legíti]ma a la dicha doña Juana de Zúñiga e a la dicha María Cortés por su hija". ${ }^{59} \mathrm{El}$ testamento de Cortés se abrió al día siguiente de su fallecimiento y Gómara, que no se encontraba a su lado, debió de tener acceso a su lectura a través de alguien de la casa del marqués, probablemente en Valladolid en los primeros meses de 1548.

Por lo que respecta al marqués de Astorga, Pedro Álvarez Osorio, declara conocerlo "de dicinueve años a esta parte [poco] más o menos", es decir poco después que a Cortés. El encuentro pudo tener lugar con motivo del viaje a Italia con el emperador, pues Gómara da noticia en las Guerras de mar de su presencia y protagonismo. ${ }^{60} \mathrm{Al}$ que sería $\mathrm{V}$ marqués de Astorga, Álvaro Pérez Osorio, sin duda lo conoció en la corte, en compañía de su padre. Bien pudo ser el escenario Valladolid pues los "cinco años a esta parte poco más o menos" que declaró al ser preguntado sitúan el encuentro hacia 1544-1545, fechas en las que Gómara está en la corte.

56 M. ${ }^{a}$ del Carmen Martínez Martínez (ed.), En el nombre del hijo. pp. 55-60.

57 Díaz del Castillo, Historia verdadera, CXCV, p. 368.

58 López de Gómara, Historia de la conquista, CXCIV, p. 273. El conde de Aguilar formó parte de la comitiva que acompañó a don Carlos a Italia en 1530, ocasión en la que también se comprueba la presencia de otros ilustres miembros de los Zúñiga y de los Arellano. López de Gómara, Guerras de mar, pp. 126-127.

59 ARChV, Pleitos Civiles, Masas, Fenecidos, 3351-2. Probanza de los testamentarios de Hernán Cortés. Declaración de López de Gómara, Valladolid, 26 enero de 1549.

60 López de Gómara, Guerras de mar, p. 126. 


\section{El reencuentro de López de Gómara y Cortés}

A partir de 1530, y durante más de una década, Cortés y Gómara siguieron caminos diferentes. El marqués regresó a la Nueva España y el cronista tuvo la oportunidad de conocer Roma, Bolonia y Venecia durante sus estancias en la península italiana ${ }^{61} \mathrm{El}$ reencuentro se produjo después del segundo retorno a España de Cortés, que desembarcó en Sanlúcar en los primeros días de abril de 1540. En la obra de Gómara, que por aquellas fechas se encontraba en Venecia, el viaje fue despachado con brevedad en el epígrafe "Muerte de Fernando Cortés" y en el que, además, sintetizó los últimos siete años de vida del marqués del Valle, curiosamente los que pudo conocer más de cerca. Frente a los precisos comentarios dedicados a las circunstancias del viaje de 1528, la información sobre el de 1540 es más bien escasa. Del primero, con la concisión que le caracteriza, reflejó algunas de las muchas razones que lo motivaron, recordó los nombres de algunos de sus acompañantes, se detuvo en su boda con Juana de Zúñiga, en el regreso a México y en la destitución de la primera Audiencia. ${ }^{62}$ Del segundo se limitó a señalar sus diferencias con el virrey Mendoza, la presencia de sus hijos Martín, el heredero, y Luis y que vino rico y acompañado, mas no tanto como la primera vez. ${ }^{63}$

Gómara y Hernán Cortés coincidieron de nuevo en el desafortunado escenario de Argel $^{64}$ y luego en la metrópoli en diversos lugares. Aunque no podamos afirmar que vivieron bajo el mismo techo, si es posible situar a ambos en Valladolid y Madrid entre 1544-1546. Se sabe que Cortés vivió en Valladolid, aunque no de forma continuada, al regreso de Argel, como ha quedado constancia en los documentos notariales ${ }^{65}$ Cuando la corte se trasladó a Madrid el marqués del Valle mudó allí su residencia, donde ya se encontraba a comienzos de 1546. A finales de octubre partió para Sevilla, instalándose después en Castilleja de la Cuesta, donde falleció el 2 de diciembre de 1547. Gómara refiere haber visto a Cortés en Valladolid y Madrid, aunque tan sólo en su declaración concreta dos situaciones que pueden fecharse.

61 Jiménez, Francisco López de Gómara, pp. 53-93.

62 López de Gómara, Historia de la conquista, CXCII-CXCVI, pp. 271-276.

63 Ibidem, CCLI, p. 335.

64 Jiménez, Francisco López de Gómara, pp. 95-98.

65 Luis Fernández Martín, "Hernán Cortés y su familia...”, pp. 309-349, pp. 312-314. 


\section{El concierto de la boda de María Cortés}

Hernán Cortés y el marqués de Astorga firmaron las capitulaciones matrimoniales de sus hijos en el monasterio bernardo de Nuestra Señora de la Espina, a cinco leguas de Valladolid. El concierto fue fechado el 30 de julio de 1545, aunque los letrados del marqués del Valle que redactaron el interrogatorio para la probanza de 1549 hablan del 4 de septiembre al referirse a aquella jornada.

¿Qué sabía Gómara de aquellos acontecimientos? Además de la información que le proporcionan otras personas, el cronista dispone de sus propias referencias. Contempló la numerosa comitiva que acompañó a Cortés cuando acudió a la cita con el marqués de Astorga con motivo del compromiso de sus primogénitos. Por ello, declaró:

que lo que sabe es que el año de cuarenta y cinco o cuarenta y cuatro, que claramente no se acuerda qué año era, mas de que se acuerda que era por el mes de setiembre, este testigo vio ir al marqués del Valle e a otros muchos caballeros y presonas ( sic) con el dicho marqués del Valle al monasterio del Espina e decían que iban [a] hacer el dicho concierto de desposorios entre el dicho don Álvar Pérez Osorio e doña Ma[ría] Cortés, e que cuando vinieron a esta villa [del] dicho monasterio dijeron a este testigo mu[chas] presonas de las que se habían halla[do] presentes cómo quedaba hecho [...] concierto entre los dichos marqueses [...] y vio este testigo como muchas personas daban e dieron el parabién de los dichos conciertos y capitulaciones al dicho marqués; y aún este testigo tuvo en su poder las dichas capitulaciones e las leyó e que por esta causa tiene por cierto este testigo que se hizon (sic) los dichos conciertos e que estaban firmados los dichos conciertos de los dichos dos marqueses e que esto es lo que sabe desta pregunta. ${ }^{66}$

Lo dicho por Gómara arroja luz sobre diversas cuestiones, suscita interrogantes y sorprende con alguna de sus afirmaciones. Así confirma su presencia en Valladolid en 1544-1545 y llama la atención que no sea capaz de fijar el año del acuerdo. Aunque afirmó haber leído las capitulaciones matrimoniales, fechadas en julio de 1545, el mes que recuerda con claridad es septiembre. Quizás entonces volvieron a reunirse los marqueses del Valle y de Astorga y se conoció públicamente el compromiso, de ahí las felicitaciones que recibió el primero de "muchas personas" y que contempló, sin especificar si fue en un espacio público o privado.

66 ARChV, Pleitos Civiles, Masas, Fenecidos, 3351-2. Probanza de los testamentarios de Hernán Cortés. Declaración de López de Gómara, Valladolid, 26 enero de 1549. 
Tal vez la noticia del compromiso lo animó a dedicar al marqués de Astorga el texto que sobre los Barbarroja había resumido en el caluroso verano de 1545, entre otras razones — justificaba - "porque habéis tomado deudo con el marqués del Valle, cuya historia yo escribo, casando a don Álvaro Pérez de Ossorio, vuestro hijo mayor, con su hija mayor doña María". Recordemos que la fecha de la dedicatoria es el 5 de septiembre de 1545, justo al día siguiente de los acontecimientos que declaró recordar.

Por otra parte, si bien las palabras de Gómara confirman su condición de testigo de las felicitaciones que recibió el marqués del Valle, no aclaran dónde, ni en calidad de qué, contempló al grupo que lo acompañaba, ni si estos, antes de partir, explicaron el motivo de la jornada a intercesión suya o porque en él se encontraban algunos conocidos o si simplemente escuchó los comentarios que hacía un grupo de jinetes que, engalanados para la ocasión, no dejarían de llamar la atención. Lo que queda claro es que él no estuvo en La Espina acompañando a Cortés, ausencia inexplicable si hubiese escrito a petición del conquistador o en aquellas fechas fuese su capellán.

\section{De Madrid a Sevilla}

En 1546, tras el traslado de la corte de Valladolid a Madrid, hay constancia de que Gómara y Cortés coincidieron de nuevo. La información la proporciona el cronista al reconocer que fue testigo de la apresurada salida del marqués hacia Sevilla, convencido de que su hija María llegaría tan presto como él. Por ello dijo que "lo que sabe es que vio muchas veces este testigo al dicho marqués del Valle hablar en ello con gran gana e muestra de que viniesen luego sus hijas dentro del término capitulado e que, pensando que vernían ya u que tenía por cierto que [s]erían venidas, le vio este testigo partir de la villa de Madrid al tiempo que [la] pregunta dice para Sevilla". ${ }^{67}$ En La Conquista de México amplió la finalidad del viaje al señalar que "Fue a Sevilla con voluntad de pasar a la Nueva España y morir en México y a recibir a doña María Cortés" e hizo expresa mención a que "Iba malo de cámaras e indigestión". ${ }^{68}$

Gómara, por lo tanto, no acompañó a Cortés a Sevilla, aunque es innegable que durante los meses que estuvo en Madrid lo vio muchas

67 Ibidem.

68 López de Gómara, Historia de la conquista, CCLI, p. 336. 
veces, pues así lo afirma, tal vez en las visitas que pudo hacer a su casa por la amistad que le unía a algunos de sus allegados o en las salidas del marqués. Quien si estuvo al lado de Cortés en la jornada fue Pedro de Ahumada. El cronista no fue testigo de los preparativos que el marqués del Valle hizo en Sevilla para la boda de su hija, ni de la compra de vestidos, brocados y tapicería para su recibimiento, pero si tuvo noticia de ellos porque: "de ahí a poco tiempo vio este testigo cartas del dicho marqués hechas en Sevilla e que oyó decir que el dicho marqués hacía el dicho aparejo en la pregunta contenida e ansimesmo vio este testigo como en las cartas que el dicho marqués enviaba, enviaba a mandar que le comprasen dos mulas que fuesen muy buenas para las dos hijas que habían de venir y él esperaba". ${ }^{69}$

El destinatario de las cartas evidentemente no era Gómara, pues de haber sido así no lo habría silenciado. Sin duda estaban dirigidas a quienes atendían sus asuntos, tal vez a Pedro de Ahumada, quien después de acompañarlo hasta Sevilla viajó a la corte, o a Francisco Sánchez de Toledo, a quien Cortés encargó la compra de las cabalgaduras mencionadas, o a don Juan de Castilla, como se deduce de las partidas asentadas en las cuentas del marqués..$^{70}$ Son tan sólo algunos nombres de los muchos posibles.

Gómara fue testigo del último gran empeño de Cortés, la boda de su hija, pues, como reconoció al responder a la décima pregunta, "antes de que se fuese a Sevilla el dicho marqués le vio e oyó decir que no tenía mayor deseo que ver venir a su hija doña María Cortés e ca[sa]da con el dicho don Álvaro e que [a]simesmo oyó decir este testigo a [otras] muchas personas que cuan[do esta]ba el dicho marqués en Sevilla [siempr]e tuvo el dicho deseo". ${ }^{71}$

López de Gómara, pese a que no estuvo en Sevilla, no tiene ninguna duda de que Cortés hizo todo lo posible para cumplir con los plazos acordados en el concierto de boda, pues así se lo oyó antes de que abandonase Madrid y a otros muchos después de que con aquel fin se instalase en Sevilla. Por lo tanto no podía imputársele negligencia ni culpa alguna en la cancelación de la boda de su hija, pese a que la joven no llegó a España en el plazo fijado en el acuerdo.

69 ARChV, Pleitos Civiles, Masas, Fenecidos, 3351-2. Probanza de los testamentarios de Hernán Cortés. Declaración de López de Gómara, Valladolid, 26 enero de 1549.

70 Antonio Muro Orejón, Hernando Cortés, p. 61.

71 ARChV, Pleitos Civiles, Masas, Fenecidos, 3351-2. Probanza de los testamentarios de Hernán Cortés. Declaración de López de Gómara, Valladolid, 26 enero de 1549. 
El testimonio de Gómara permite concluir que desde que Cortés salió de Madrid, en la segunda quincena de octubre de 1546, hasta que falleció en Castilleja de la Cuesta, no volvieron a coincidir. Esta circunstancia explica que no fuese examinado por las preguntas que expresamente trataban de María, a la que no conocía en el momento de declarar, o de las gestiones realizadas por Cortés en Sevilla para procurar el viaje de su hija. Del último año de vida del marqués del Valle tuvo conocimiento por terceras personas con las que se carteaba Cortés, como se deduce de su declaración: "en todo el tiempo desde que el dicho marqués allegó a Sevilla estuvo allí o en Castilleja, donde murió, esperando a las dichas sus hijas para casar luego que fuese venida la dicha doña María con el dicho don Álvaro Osorio lo (sic) e que esto lo oyó este testigo muchas veces por cartas que vio del dicho marqués". ${ }^{2}$

\section{"De vista, habla e conversación" y "Que ayude Dios al que tuviere justicia"}

La primera impresión que suscita la lectura de la declaración de Gómara es la de un privilegiado espectador de la vida de Cortés en España pues "le vio e oyó decir" y que, además, cuenta con una amplia red de informantes y relaciones dado que utiliza expresiones del tipo: "al que dijeron" o "que oyó decir". Mas si sus palabras lo presentan como persona que está al corriente de lo que ocurría en la casa del marqués del Valle, incluso testigo de algunos de sus movimientos, en absoluto permiten afirmar que tuviese un papel en el círculo cortesiano más allegado o que existiese entre ellos algún vínculo o relación remunerada. Sobre los motivos que justifican su presencia al lado de Cortés no podemos ofrecer conclusiones definitivas, aunque sí aclarar cómo y a través de quién o quiénes tiene acceso a su casa y a la lectura de los capítulos matrimoniales acordados con el marqués de Astorga, el testamento de Cortés o las cartas privadas y despachos que afirma haber visto, aunque silencie dónde y en calidad de qué. ¿Qué trato tenía el clérigo con el marqués del Valle?

En las preguntas generales del interrogatorio los testigos, para evitar recusaciones, debían decir la relación que mantenían con los litigantes. Era el momento de que Gómara declarase cualquier vínculo que tuviese con

72 Ibidem. 
Cortés, más aún si era su capellán o recibía salario de él. Sin embargo sólo dijo: "que no es pariente de ninguna de las dichas partes ni menos ha sido atraído ni inducido, corruto ni atemorizado por ninguna de las dichas partes, porque hobiese de decir el contrario de la verdad, sino que ayude Dios al que tuviere justicia". ${ }^{73}$

En este punto consideramos conveniente comparar su declaración con las de los otros testigos para valorar su relación con los marqueses del Valle. Juan Altamirano dijo que "era primo de Fernando Cortés"; fray Diego Altamirano que "era pariente del marqués del Valle que agora es [Martín Cortés] e de su padre"; Pedro de Ahumada declaró ser "camarero del marqués" y el licenciado Hernando de Chaves que "tiene salario de letrado del duque de Medina Sidonia". Aclaraciones similares realizaron los testigos que declararon en Logroño o Sevilla, entre ellos Gonzalo Díaz, que no ocultó que "fue criado del marqués del Valle, don Fernando Cortés, e lo sirvió de paje e camarero e a este marqués del Valle, don Martín, lo sirve de caballerizo e es su criado", o Melchor de Múxica, que declaró que "fue contador del dicho don Hernando Cortés, marqués del Valle ya defunto, e al presente lo es del dicho don Martín Cortés". Los testigos presentados por el marqués de Astorga en sus probanzas tampoco silenciaron sus vínculos con Hernán Cortés. Así, Pedro García declaró que conoció a Cortés y a su hijo Martín "por vista, habla, trato e conversación que con ellos ha tenido e tuvo e porqu[e] este testigo fue criado del dicho marqués del Valle defunto ... e que al tiempo que se hicieron los dichos capítulos contenidos en la dicha pregunta ... este testigo se halló en el dicho monesterio porque a la sazón vivía con el dicho marqués del Valle defunto". ${ }^{74}$ Por su parte, el doctor Espinosa puntualizó "que al tiempo que se ordenaron los casamientos sobre que es este pleito y agora llevaba este testigo salario del marqués del Valle que fallesció y lo lleva de su hijo".

Frente a la clara respuesta de casi todos los testigos a la hora de establecer su relación con Hernán Cortés y su hijo, Gómara nada dice sobre que fuese capellán del conquistador, ni que viviese en su casa, ni que en su nombre realizase trabajo alguno o escribiese algo. De hecho, entre los contemporáneos del cronista tan sólo Las Casas lo consideró su capellán. ${ }^{75}$

73 Ibidem.

74 Ibidem. Declaración de Pedro García, Astorga, 3 de marzo de 1549.

75 Bartolomé de las Casas, Historia de las Indias, tomo II, pp. 449-450. Ni Andrés de Tapia, con el que trató Gómara, ni Francisco Cervantes de Salazar, ni Bernal, ni el inca Garcilaso dicen nada al respecto. Véase Jiménez, Francisco López de Gómara, p. 102. 
Gómara se limita a declarar que los conoce "de vista e habla e conversación". En términos similares podríamos considerar lo dicho por Alonso de San Clemente, alcaide de Nalda, que, al igual que él, conocía a los litigantes sin mantener aparentemente con Cortés ninguna relación especial. No obstante, la atenta lectura de las declaraciones de ambos permite establecer claras diferencias en el trato que uno y otro mantenían con el conquistador. De los labios de Gómara no salió ninguna palabra que permita afirmar que el marqués del Valle le dijese algo directamente o le escribiese, circunstancia que si se advierte en San Clemente pues "hablando este testigo con el dicho marqués del Valle le dijo a este testigo muchas veces cómo había concertado" la boda de su hija. ${ }^{76}$

Lo dicho más bien parece indicar que Las Casas lo hiciese capellán de Cortés en sentido despectivo, para señalar su excesiva admiración por el conquistador y su falta de objetividad al escribir sobre él. Si hubiese sido su capellán en 1545 habría estado presente en el monasterio de La Espina cuando se concertó la boda de María o, al menos, hubiera tenido información de primera mano. En noviembre de ese año lo era Gaspar de Burguillos, clérigo a quien el propio Cortés trató como "mi capellán" en un poder notarial. ${ }^{77} \mathrm{Si}$ Gómara hubiese sido su capellán en 1546-1547 lo habría acompañado a Sevilla y permanecido a su lado hasta su muerte, pero no lo hizo. Quienes fueron retribuidos por tal oficio en aquellos años fueron los clérigos Miguel de Arriaga y Jorge de Guzmán. ${ }^{78}$

\section{Las amistades de López de Gómara en la casa del marqués del Valle de Oaxaca}

Por lo escrito en La Historia de las Indias y conquista de México y lo declarado en la probanza no cabe ninguna duda de que Gómara estaba muy bien informado sobre los asuntos de Hernán Cortés. ¿Cuáles fueron sus fuentes de información?

76 ARChV, Pleitos Civiles, Masas, Fenecidos, 3351-2. Probanza de los testamentarios de Hernán Cortés, marqués del Valle, en el pleito con el marqués de Astorga. Declaración de Alonso de San Clemente, Valladolid, 26 de enero de 1549.

77 Archivo Histórico Provincial de Valladolid, Valladolid (en adelante AHPV), 117. Poder de Hernán Cortés para seguir sus pleitos a favor de Juan de Hontiveros, Gonzalo de Oviedo, Juan del Valle, Juan Pérez de Salazar y Gaspar de Burguillos, clérigo, Valladolid, 23 de noviembre de 1545.

78 Muro, Hernando Cortés, pp. 48 y 57. 
En la mayoría de las ocasiones el cronista conoce los hechos sobre los que declara por la relación que le facilitan terceras personas, hecho que resume el recurrente uso de expresiones del tipo "dijeron a este testigo" o "ha oído decir". En otros casos, por fortuna, concreta el nombre de sus informantes mencionando a Andrés de Tapia, conquistador, y a Jaime Campos y Antón Arias, contadores de Hernán Cortés y Pedro Álvarez Osorio. Aunque en la probanza no lo señale, conocía y trataba a Pedro de Ahumada, secretario del marqués del Valle viejo y camarero de su heredero.

Frente al "oyó decir" de Gómara los parientes, servidores y criados del marqués refieren sus experiencias personales. Así, Pedro de Ahumada manifestó abiertamente que tenía noticia de los hechos sobre los que declaró porque vivía en Valladolid en casa de Cortés, lo que le permitió ser testigo directo de sus actuaciones y manifestar por ello que "se halló presente". Además, como secretario del marqués del Valle, escribió cartas a su dictado, por lo que conocía la situación y sentimientos de Cortés de primera mano. En definitiva, declaró con seguridad porque "estaba con el dicho marqués e sabe e vio cómo pasó todo lo en la pregunta contenido por andar siempre en su compañía". ${ }^{79}$ Idéntica familiaridad y trato directo se comprueba en la declaración de fray Diego Altamirano, pues "a este testigo le envió a llamar el dicho marqués del Valle [a la] villa de Benavente para tomar con [este] testigo su parecer sobre el dicho concier[to conte]nido", o porque "el dicho marqués contó a este testigo", además de que conocía los hechos por "todas las veces que este testigo habló con el dicho marqués del Valle, que fueron muchas" ${ }^{80}$ Incluso Gonzalo Díaz, paje y camarero, afirma que "trataba e conversaba con el dicho marqués del Valle muy ordinariamente". ${ }^{81}$

Frente a testimonios tan elocuentes y explícitos, en el caso de Gómara no hay ninguna expresión que ponga en evidencia su trato directo con Cortés o su condición de confidente, pues en ningún momento deslizó el uso de la primera persona para indicar que el conquistador, en aquel u otros negocios, le hubiese dicho algo o escrito alguna vez. Lo que es innegable es que, desde una discreta segunda fila, conoce ciertos aspectos de su vida, sin duda por las buenas relaciones que tiene con sus servidores, a los que

79 ARChV, Pleitos Civiles, Masas, Fenecidos, 3351-2. Probanza de los testamentarios de Hernán Cortés, marqués del Valle, en el pleito con el marqués de Astorga. Declaración de Pedro de Ahumada, Valladolid, 26 enero de 1549.

80 Ibidem. Declaración de fray Diego Altamirano, Valladolid, 28 de enero de 1549.

81 Ibidem. Declaración de Gonzalo Díaz, Logroño, 11 de marzo de 1549. 
visita y con los que trata, lo que le facilita el acceso a su casa y le proporciona una posición privilegiada para observar, indagar e incluso conversar con el propio marqués si se presentaba la ocasión. Recordemos que Gómara, cuando se concertó el compromiso de María Cortés, ya había decidido que Cortés sería el protagonista de la segunda parte de La Historia de las Indias y que este conocería su propósito pues constaba en la dedicatoria a su futuro consuegro de Los corsarios Barbarroja. La obra, inevitablemente, uniría su nombre al del marqués del Valle y al de su heredero, al que dedicó lo escrito sobre su progenitor.

Hernán Cortés se deleitaba en tener mucha casa y compañía, de ahí que su presencia en la corte no pasase desapercibida. Gómara bien pudo contemplarlo o tropezarlo, al igual que otros muchos transeúntes, en sus salidas y paseos. Sabemos que el marqués del Valle de Oaxaca se instaló en Valladolid en la casa que Rodrigo Enríquez construyó en la parroquia de San Lorenzo, próxima al río Pisuerga. Dependencia que tal vez visitó Gómara por la relación que mantenía con los servidores de la casa de este noble, como abiertamente reconoció al afirmar que lo declarado sobre la boda de María lo sabía "por la amistad y entili[gencia que] tiene en casa del marqués e [... cri]ados" ${ }^{82}$ En nuestra opinión, las palabras de Gómara no revelan su amistad con Cortés sino que aclaran y puntualizan que es con la casa del marqués, lo que sin duda posibilitó su acceso al conquistador. Aquella amistad con personas concretas del entorno cortesiano le permitió, con el paso de los años, continuar la relación con el segundo marqués del Valle, como señalaremos más adelante.

Pese a la relación distante que parece tener con Cortés llama la atención su afirmación "y aún este testigo tuvo en su poder las dichas capitulaciones e las leyó". ¿Quién facilitó a Gómara el acceso al documento? La clave está en la estrecha relación que mantiene con esa casa nobiliaria. Sabemos de su trato con Jaime Campos y Antón Arias, contadores de los marqueses del Valle y de Astorga, con quienes conversó y a quienes "les oyó decir algunas veces" cómo había cumplido el marqués del Valle con el primero de los plazos estipulados en la entrega de la dote de doña María Cortés pues "él no se halló presente cuando el dicho marqués del Valle ni otro en su nombre dio al dicho marqués de Astorga los dichos veinte mil ducados". ${ }^{83}$ Sabedor de los plazos y cantidades fijadas para cumplir con los

82 Ibidem. Declaración de López de Gómara, Valladolid, 26 enero de 1549.

83 Ibidem. 
100.000 ducados de la dote, porque había leído "muchas veces las capitulaciones", se remitió al texto del concierto, obviando con ello cualquier aclaración. Jaime Campos vivía con Cortés y cumpliendo sus órdenes se ocupó de pagar al escribano que suscribió el acuerdo matrimonial y llevó la cuenta de las cantidades entregadas al marqués de Astorga en pago de los veinte mil ducados. Bien pudo ser él su informante, aunque no era el único en situación de hacerlo.

Ya hemos señalado como la estrecha amistad con algunos criados y allegados de Cortés le permitió acceder a sus papeles, despachos y cartas privadas. Por ello puede afirmar que el marqués del Valle hizo cuanto pudo para cumplir con los plazos fijados en el concierto matrimonial con el marqués de Astorga. En este sentido, la breve respuesta que inicialmente dio cuando se le formuló la quinta pregunta del interrogatorio, "que la sabe como en ella se contiene", fue puntualizada cuando "Preguntado cómo, por qué lo sabe, dijo que porque este testigo vio los despachos e cartas que el dicho marqués del Valle escribía a su mujer muchas veces y a sus fatores y gobernador, que era y es el licenciado Altamirano, para que con la dicha doña María, su hija, le enviasen cantidad de dineros para cumplir con los dichos conciertos e que por esta causa sabe lo en la pregunta contenido". ${ }^{84}$

El comentario de Gómara nos lleva a tratar de identificar a la persona que le mostró los escritos privados de Cortés, pues si hubiese sido el marqués lo habría declarado, cosa que no hace, al contrario que otros testigos. Por lo tanto tenemos que pensar en alguien muy cercano al marqués en aquellos momentos, que residiese en su casa y gozase de su confianza. Creemos que esa persona fue el ya varias veces citado Pedro de Ahumada, ${ }^{85}$ a quien Gómara conoció y trató y del que escribió que era "muy entendido en muchas cosas y muy virtuoso hidalgo, con quien yo tengo amistad estrecha". ${ }^{86}$

Por la declaración de Ahumada en el pleito sabemos que vivía con el marqués, que se encontró presente en la firma de los conciertos matrimoniales y que escribió cartas informando a doña Juana de Zúñiga del acuerdo ${ }^{87}$ Pedro de Ahumada, natural de Santo Domingo de la Calzada, había

84 Ibidem.

85 Fue administrador del marquesado y de sus posesiones en Nueva España. Véase Bernardo García Martínez, El marquesado, p. 162.

86 López de Gómara, Historia general, XLV, p. 65. Véase Jiménez, Francisco López de Gómara, p. 107.

87 ARChV, Pleitos Civiles, Masas, Fenecidos, 3351-2. Probanza de los testamentarios de Hernán Cortés. Declaración de Pedro de Ahumada, Valladolid, 26 de enero de 1549. 
regresado con Cortés en 1540, anduvo en su compañía durante aquellos años y después de su fallecimiento continuó al servicio del sucesor del Marquesado. Sin duda fue uno de los confidentes de López de Gómara.

A quien si menciona López de Gómara entre sus informantes es a Andrés de Tapia. Este fue uno de los asiduos acompañantes de Cortés en aquellos años, tanto en Valladolid como en Madrid. Frecuentemente cabalgó con el marqués y se alojó en su casa. El cronista lo menciona a propósito de las acusaciones que responsabilizaban a Cortés y a Juana de Zúñiga, la marquesa, de estorbar el viaje de su hija a España. Frente a ello declara que "ha oído decir a muchas personas que de México vinieron a España, después que allá llegó la nueva del desposorio, como la marquesa del Valle doña Juana de Zúñiga se había alegrado de la nueva, e había luego adrezado (sic) sus hijas para el camino y había hecho el matalotaje en que especialmente se lo oyó decir este testigo a Andrés de Tapia, conquistador, e a criados del marqués del Valle, e que esto es lo que sabe e ha oído decir". ${ }^{88}$ Años más tarde, una breve y contundente frase "Mas no se casaron por culpa de don Álvaro y de su padre", ${ }^{89}$ puso en evidencia a quien achacó el cronista la cancelación de la boda. Por aquellas fechas las sentencias pronunciadas en el pleito con el marqués de Astorga, en el que Gómara testificó, le daban la razón. ${ }^{90}$

La respuesta de Gómara tiene el interés de incluir a Andrés de Tapia entre las personas con las que tuvo trato. Recordemos que Tapia es autor de una relación de la empresa cortesiana que algunos autores han señalado que Gómara saqueó y plagió. ${ }^{91}$ Lo cierto es que la coincidencia en los mismos escenarios le permitió contar con su testimonio oral, sin duda bien aprovechado en cuantos asuntos del Nuevo Mundo tuvo curiosidad, al margen de que pudiese consultar o no su obra escrita. En este sentido su afirmación confirma la veracidad del comentario que deslizó en La Conquista de México, cuando escribió "Andrés de Tapia, que me lo dijo"92 y su relación con él.

88 Ibidem. Declaración de López de Gómara, Valladolid, 26 enero de 1549.

89 López de Gómara, Historia de la conquista, CCLI, p. 336.

90 ARChV, Registro de Ejecutorias, 750-2. Ejecutoria a favor del marqués del Valle en el pleito con el marqués de Astorga, Valladolid, 16 de enero de 1552. ARChV, Pleitos Civiles, Masas, Fenecidos, 3351-2. Sentencias de vista y revista en el pleito de los testamentarios de Hernán Cortés con el marqués de Astorga, Valladolid, 10 de marzo de 1550 y 25 de septiembre de 1551.

91 Germán Vázquez (ed.), La conquista de Tenochtitlan, p. 62. En este título el editor incluyó la Relación de algunas cosas de las que acaecieron al muy Ilustre señor don Fernando Cortés, marqués del Valle, desde que se determinó ir a descubrir en la Tierra Firme del Mar océano escrita por Andrés de Tapia.

92 López de Gómara, Historia de la conquista, LXXXII, p. 120. 
López de Gómara también declaró haber oído "muchas veces por cartas que vio del dicho marqués" que este, durante su estancia en Sevilla y Castilleja de la Cuesta, esperaba la llegada de su hija María y realizaba los preparativos para la boda, como ya se ha indicado. A pesar de que silencia el nombre de los destinatarios de aquellas cartas que "vio" y "oyó", alguien las leyó o comentó en voz alta. Sin duda estaban dirigidas a algún hombre de confianza de Cortés. Si él hubiera sido el receptor debería haberlo declarado, como lo hizo el licenciado Hernando de Chaves al acreditar que "lo supo del dicho marqués por sus cartas que dél recibía”, o fray Diego Altamirano al recordar las "muchas cartas que el marqués a este testigo escribió", quien además puntualiza que era "la persona con quien el dicho marqués, en secreto y en público, más cosas comunicaba". Además de emplear la primera persona, su testimonio pone de manifiesto las conversaciones y confidencias que le hizo el conquistador en Sevilla durante sus últimos meses de vida:

\begin{abstract}
que cuando este testigo fue a ver al dicho marqués, cuando estaba malo el dicho marqués, y todos sus amigos y criados dijeron a este testigo que la causa de todo su mal del dicho marqués era de pesar de ver que sus hijas se tardaban y aún ansí lo conoció este testigo en el marqués porque, hablando este testigo con él, por le alegrar, le nombraba la venida de sus hijas y el efeto del casamiento muchas veces y con esto sentía este testigo en el dicho marqués que se alegraba y aún este testigo y el dicho marqués platicaron muchas veces en las fiestas e regocijos que se habían de hacer cuando el dicho don Álvaro viniese a efetuar el dicho casamiento y el recibimiento que le había de hacer al dicho don Álvaro y a los que con él viniesen, las joyas y cosas que pensaba dar a cada uno. ${ }^{93}$
\end{abstract}

\title{
López de Gómara y los hijos de Hernán Cortés: "Amistad e conversación"
}

El trato de Gómara con los servidores y criados del marqués del Valle se mantuvo tras la muerte de Hernán Cortés. Los más allegados continuaron al servicio de su hijo, entre ellos Pedro de Ahumada, Diego Ferrer, Gonzalo Díaz, Juan López de Vergara y Mariano de Verona, asiduos acompañantes del segundo marqués del Valle en los años siguientes. Aquella circunstancia posibilitó que Gómara, que ya conocía a Martín Cortés, cultivase su amistad y tuviese la oportunidad de tratar a sus hermanas.

93 ARChV, Pleitos Civiles, Masas, Fenecidos, 3351-2. Probanza de los testamentarios de Hernán Cortés. Declaración de fray Diego Altamirano, Valladolid, 28 de enero de 1549. 
El heredero de este Marquesado había nacido en Cuernavaca en 1532. Su padre lo trajo a España en 1540 siendo todavía un niño. No hay que confundirlo con su hermano de padre y homónimo, el hijo de doña Marina, que vino a la corte con su progenitor en 1528. Debió de ser este último, por entonces de unos veinte años, quien estuvo con su hermano Luis en Argel al lado del padre. Aunque Bernal Díaz del Castillo sitúa en aquel escenario a los dos Martín, ${ }^{94}$ Gómara registró la presencia de Martín y Luis sin puntualizar que se tratase del heredero o "mayorazgo" como lo hace en otras ocasiones. ${ }^{95}$

Cuando Hernán Cortés regresó a Castilla en 1540 Gómara se encontraba en Italia, desde donde al año siguiente se incorporó a la empresa de Argel. ${ }^{96}$ Conoció a don Martín en 1542, tal y como se deduce de su declaración de agosto de 1551 donde afirmó que era "desde nueve años a esta parte", siendo entonces más preciso que en enero de 1549 cuando declaró que hacía siete u ocho años más o menos.

En vida de Hernán Cortés conocía a don Martín de "vista e habla e conversación", como a su padre. Así siguió en los años inmediatamente posteriores a su muerte. Gómara y el segundo marqués coincidieron de nuevo en Valladolid en la cuaresma de 1548. El cronista en aquella ocasión venía de Aranda de Duero, donde residían los Consejos, y:

vio e habló entrambos, los dichos marqueses de Astorga e del Valle, en casa del conde de Benavente, donde posaba el dicho marqués de Astorga, e que el dicho marqués del Valle vino de Sevilla a la ligera, según lo oyó decir a la sazón, e ansí vio que la cámara e aposento donde el dicho marqués del Valle e conde de Agilar (sic), su curador, posaban estaban adrezadas de arreos del marqués de Astorga e ansí los vio este testigo comer juntos a los dichos marqueses siete ocho días que este testigo estuvo en esta villa. ${ }^{97}$

Lo que se deduce de su declaración es que tuvo la oportunidad de hablar al hijo de Cortés y al marqués de Astorga en la casa del conde de Benavente, ${ }^{98}$ en la que tal vez se alojó pues, durante los siete u ocho días que estuvo en Valladolid, fue testigo de que ambos nobles compartieron

94 Díaz del Castillo, Historia verdadera, CCIV, p. 416.

95 López de Gómara, Historia de la conquista, CCLI, pp. 335-336.

96 Jiménez, Francisco López de Gómara, p. 95.

97 ARChV, Pleitos Civiles, Masas, Fenecidos, 3351-2. Probanza de los testamentarios de Hernán Cortés. Declaración de López de Gómara, Valladolid, 26 de enero de 1549.

98 Alonso Pimentel, V conde de Benavente, era el suegro del marqués de Astorga, padre de María Pimentel, su primera mujer. El palacio era uno de los edificios más destacados de la ciudad en aquellas fechas. Jesús Urrea, Arquitectura y nobleza. p. 43. 
mesa. Las dependencias ocupadas por don Martín traducían la hospitalidad del marqués de Astorga, pues eran sus arreos los que adornaban la cámara y aposento que ocupó, como tuvo ocasión de ver. Nada apuntan sus palabras a que conociese el contenido de sus conversaciones, solamente que las mantuvieron. Tampoco parece que fuese Martín Cortés el que le explicase las circunstancias que le hicieron abandonar Sevilla a la ligera, sino que "lo oyó decir". Al lado de don Martín se encontraban, entre otros, Pedro de Ahumada, Diego Ferrer y Melchor de Múxica, a quienes pudo escuchar el comentario. Una vez más el testimonio de Ahumada aclara el contenido de aquellas conversaciones en las que el marqués de Astorga solicitó 6.000 ducados de la dote prometida antes de la llegada de María Cortés, petición a la que accedió, en nombre del marqués del Valle, su curador, el conde de Aguilar.

En enero de 1549 se produjo la declaración de Gómara en el pleito del marqués contra el marqués de Astorga, aunque ello no indica que tratase estrechamente con Martín Cortés que por aquellas fechas residía en Nalda con el conde de Aguilar. Allí, en febrero de ese año casó con su prima Ana de Arellano.

De nuevo aparece Gómara en agosto de 1551 en Valladolid, en esta ocasión como testigo en el litigio de los Aranda con el segundo marqués del Valle. El clérigo de Osma, tras prestar juramento, declaró que:

Conoce al dicho marqués del Valle, don Martín Cortés, e a doña María e doña Catalina e doña Juana, sus hermanas, e sabe que los susodichos ni alguno dellos no tienen villas ni lugares ni vasallos ni juredición en Castilla la Vieja ni la Nueva ni en otra parte de estos reinos de España, lo cual sabe porque ha que los conoce, al marqués de nueve años a esta parte, e a sus hermanas después que vinieron de México e tiene amistad e conversación con ellos e con las personas que los conocen, e si toviesen los dichos vasallos e juredición o villas e lugares lo sabría este testigo e no podría ser menos e lo susodicho es así notorio e público entre los que los conocen; e que la villa de Nalda, donde residen los susodichos, es de don Pero Ramíres (sic) de Arellano, conde de Aguilar, señor de los Cameros, e no tiene parte alguna en ella el dicho marqués ni sus hermanos e esto es verdad..$^{99}$

Resulta evidente que el trato del cronista con Martín Cortés y su familia se había estrechado desde 1549 pues ahora dice tener "amistad e conversación" con ellos y sus allegados. En el verano de 1551 también se encontra-

99 ARChV, Pleitos Civiles, Moreno, Fenecidos, 2802-2. Declaración de Francisco López de Gómara, clérigo, para la declinatoria intención en el pleito de los hermanos Aranda con los hijos y herederos de Cortés para el cobro de cierta cantidad, Valladolid, 29 de agosto de 1551. 
ba en Valladolid el padre Las Casas, quien bien pudo verlos juntos y deducir "su residencia" en casa del marqués. Por otro lado, Gómara, tal vez intencionadamente, no hace mención alguna de la avanzada redacción de su obra.

La villa de Nalda se presenta como el escenario probable en el que Gómara conoció a las hermanas del marqués. En ella hay constancia de que se encontraban María, Juana y Catalina en el verano de 1551, pues la demanda de los Aranda fue notificada en aquel lugar al conde de Aguilar y a los hijos de Cortés "en sus personas". ${ }^{100}$ De María, la primera que hizo el viaje a España, Gómara solo tenía referencias indirectas en 1549, cuando se encontraba en Sanlúcar "donde al presente oye decir este testigo que está, e que de los dineros que trajo la dicha doña María Cortés, que vinieron consinados al duque de Medina Sidonia, su curador, sabe este testigo que se tomaron para el príncipe nuestro señor gran cantidad de ducados, según que parecerá por las escrituras que sobre ello se hicieron". ${ }^{101}$ En compañía de Martín Cortés, pese a que nada dice, tuvo que ver Gómara a su madre, doña Juana de Zúñiga, y a sus hermanos naturales, Martín y Luis, cuya presencia al lado del mayorazgo de los Cortés se rastrea, entre otros testimonios, en las cuentas del segundo marqués. ${ }^{102}$

\section{La publicación de La Historia de las Indias}

En octubre de 1552 don Martín, a sugerencia de Gómara, escribió al obispo de Arras, futuro cardenal Granvela, una elocuente carta desde Nalda. En ella presentaba a Francisco López de Gómara como "un clérigo y hidalgo muy honrrado y virtuoso y por tal está tenido" al tiempo que mostraba su deseo de que el esfuerzo que había realizado fuese recompensado y alcanzase sus peticiones porque "Hase ocupado muchos días en escriuir La ystoria de las Yndias, y según dicen, muy copiosa. Enbía un libro a Su Magestad". ${ }^{103}$

100 Ibidem. Notificación del emplazamiento de nueva demanda a petición de Antonio, Diego y Cristóbal de Aranda, vecinos de Valladolid, a Martín Cortés, marqués del Valle, a sus hermanas María, Catalina y Juana y a Pedro Ramírez de Arellano, conde de Aguilar, Nalda, 27 de julio de 1551.

101 ARChV, Pleitos Civiles, Masas, Fenecidos, 3351-2. Probanza de los testamentarios de Hernán Cortés. Declaración de López de Gómara, Valladolid, 26 de enero de 1549.

102 AHPV, 133. Fenecimiento de cuentas de la curaduría y administración que tuvo el conde de Aguilar de la persona de Martín Cortés, marqués del Valle, Valladolid, 22 de marzo de 1555.

103 RB, Fondo Granvela, II/2325, f. 110r. Carta de Martín Cortés al obispo de Arras, Nalda, 25 de octubre de 1552 . 
El propio Gómara, en noviembre, aprovechando la recomendación de Martín Cortés, también escribió desde Zaragoza al de Arras. Estaba convencido de que la privilegiada posición y formación del obispo favorecería, "si la obra lo merece", la presentación del texto ante el soberano. ${ }^{104}$ Gómara reunía méritos suficientes para lograr el apoyo solicitado, de manera que por él había "causa, y color de hablar como hablan por otros diciendo que harán y sirvirán", máxime cuando avanzaba en la carta "la compongo en latín y la acabaría presto si su magestad me ayudase". Sus palabras traducen cierta amargura pues algunos, sin hacer demostración de méritos, obtenían los reconocimientos a los que él también aspiraba, entre ellos el nombramiento de cronista.

Gómara le anunciaba que había escrito "una istoria de las yndias que intitulo y embío al emperador nuestro señor por la vía del señor don Luis de Ávila y del señor licenciado Uiruiesca [i.e. Briviesca]" ${ }^{105} \mathrm{y}$ se disculpaba por no remitirle otro por "la estrechura de camino y tiempo" y no querer importunarlo más.

La búsqueda de apoyos de personajes influyentes era frecuente entre los hombres de letras con aspiraciones en la corte, y a más de uno, entre ellos a Juan Páez de Castro, le dio muy buenos resultados años más tarde, como abiertamente reconoció en una carta a Jerónimo Zurita al aludir al apoyo del obispo de Arras y de Luis de Ávila en su nombramiento de cronista. ${ }^{106}$ Por ello, la carta también fue excusa para que Gómara expusiese sus aspiraciones: "yo pido a su Majestad título de coronista de las Indias con salario, que me haga su capellán y me dé preuilegio para sus reynos, que para Aragón el príncipe nuestro señor me lo dio". Aunque su sobrino el bachiller Juan Ruiz lo trata en un poder notarial como "coronista de su majestad" no hay constancia de que lograse aquella distinción. ${ }^{107}$ La puntualización en su carta al ámbito geográfico indiano, en el que se conside-

104 AHN, Ms. 1751, fol. 78. Francisco López de Gómara escribió en los Annales de Antonio de Perrenot, obispo de Arras, "sin duda es principal persona en negocios, consejo, lenguas y aun letras".

105 RB, Fondo Granvela, II/2252, f. 304r. Carta de Francisco López de Gómara al obispo de Arras, Zaragoza, 20 de noviembre de 1552.

106 Jiménez, Francisco López de Gómara, p. 125. Con el obispo de Arras mantuvieron correspondencia epistolar destacados humanistas de su tiempo, Valentín Moreno Gallego, "Letras misivas" pp. 31-55, pp. 52-54.

107 AHN, Órdenes Militares, Archivo Histórico de Toledo, 42.070. Poder de Juan Ruiz, en su nombre y en el de Fernán González de Almarza, chantre de la ciudad de Soria, Pedro Ruiz, clérigo, y Brígida López, testamentarios de Francisco López de Gómara, a favor del bachiller Pedro Moreno para recibir los maravedís que se adeudaban a Gómara en el momento de su muerte, Gómara, 5 de mayo de 1563 . 
ra competente y es reconocido, ${ }^{108}$ pese a que ha escrito sobre otros asuntos, no deja de ser una novedosa petición pues el primero en recibir el cargo de "Cronista y Cosmógrafo Mayor de los estados y reinos de las Indias, islas y Tierra Firme del mar oceáno" y desarrollar su cometido fue Juan López de Velasco. ${ }^{109}$ Antes que él, Juan Ginés de Sepúlveda, cronista y capellán de Carlos V, ya había proyectado escribir sobre las Indias. ${ }^{110}$ Por otra parte, sobre el nombramiento de capellán que solicita, a falta de otras referencias documentales, nada podemos aclarar. ${ }^{111}$ Finalmente, su deseo de dar a la imprenta la obra en Castilla queda patente en la petición de aquel privilegio que ya tenía para Aragón.

Curiosamente, cuando Gómara escribía al futuro cardenal Granvela, "oficialmente" no había finalizado la impresión de la edición príncipe en cuyo colofón se lee "acabose de imprimir la víspera de la Navidad de 1552”. Un mes después López de Gómara coincidió con Martín Cortés en Madrid, donde pudo mostrarle su obra impresa.

\section{López de Gómara y las deudas del segundo marqués del Valle de Oaxaca}

En su testamento de 1559 Francisco López de Gómara declaró que Martín Cortés le debía 135.000 maravedís a razón de 15.000 anuales, resultado del impago de nueve años, es decir desde 1551, sin especificar el motivo del débito. ${ }^{12}$ También declaraba que el rey le adeudaba 500 ducados de los registrados por Pedro de Ahumada para él y que se tomaron con otros dineros del marqués procedentes de Indias. Finalmente don Bernardino de Mendoza le debía 99.000 maravedís. ${ }^{113}$ Todos estos impagos derivan de los

108 En una carta de agosto de 1554 Juan Páez de Castro se refiere a Gómara como "el Historiador de Indias", Jiménez, Francisco López de Gómara, p. 123.

109 Mariano Cuesta Domingo, "Los cronistas oficiales de Indias", pp. 115-150, p. 119.

110 Jiménez, Francisco López de Gómara, pp. 117-119.

111 Ibidem, pp. 109-110, ofrece el rastreo realizado sobre su condición de capellán, aunque secundario, en la corte.

112 Tal vez aquella cantidad respondió a la cesión que Martín Cortés, en reconocimiento de su apoyo, pudo hacerle después de que declarase en el pleito con los hermanos Aranda pues hay constancia de que el marqués del Valle se encontraba en Valladolid en el mes de setiembre. AHPV, 125, fol. 683, Obligación de Martín Cortés con Antonio y Diego de Aranda por 30.000 maravedís, Valladolid, 23 de septiembre de 1551 .

113 Lewis, "El testamento", p. 75. 
tratos entre Gómara y Martín Cortés, sin que ninguno de ellos fuese satisfecho en vida del cronista.

Es bien conocido como los 500 ducados se los concedió Martín Cortés "porque hizo la corónica de la conquista de México y desa Nueva España" en los primeros días de marzo de $1553 .{ }^{114} \mathrm{El} 31$ de ese mes Gómara otorgó en Madrid dos cartas de poder que asegurasen su cobro. Por una de ellas confió su recaudación en México a Juan Altamirano, primo de Cortés, a quien había tratado en Valladolid, donde ambos coincidieron como testigos en la causa contra el marqués de Astorga. Por la otra serían Diego Ferrer, ayo del marqués del Valle, y Alonso y Pedro de Espinosa, vecinos de Sevilla, los encargados de recibir en España el dinero prometido. Sospecho que en las prevenciones de Gómara, además de su próximo viaje a Flandes, pesó el conocimiento de las cuantiosas deudas del segundo marqués y su afición por el juego.

Meses antes, el 21 de enero, Martín Cortés le había cedido a Gómara los 99.000 maravedís que había pagado por Mendoza al conde de Bailén y a Fadrique Enríquez. El clérigo se apresuró a presentar el poder en causa propia otorgado por el marqués del Valle ante el Consejo de Órdenes para cobrarlos del comendador, aunque falleció sin haberlos percibido y sin que hasta la fecha sepamos el motivo de la gratificación, muy probablemente para agradecerle algún servicio. ${ }^{115}$ El 25 de marzo el mismo marqués se obligaba a devolver a Juan de Lezcano los reales de plata que le había prestado para pagar sus múltiples deudas de juego. Entre los testigos de esta obligación, además de Mariano de Verona y Arias de Cañizales, criados del segundo marqués, aparece el clérigo Gómara. ${ }^{116}$ Tal era la situación de Martín Cortés que tres meses más tarde un alguacil sólo pudo embargarle "una capa y un sayo que tenía de su persona", todo lo demás lo había perdido apostando.

La inclinación al juego, heredada del padre, y el endeudamiento tal vez explican las palabras que con tono moralizante Francisco López de Gómara dirigió a este noble en la dedicatoria de La conquista de México:

114 Jiménez, Francisco López de Gómara, p. 105.

115 AHN, Órdenes Militares, Archivo Histórico de Toledo, 42.070. Lewis, "El testamento", p. 75, asignó a este poder, de 21 de enero, la fecha del día en que Gómara lo presentó en el Consejo de Órdenes, el 27 de ese mes.

116 AGS, Consejo Real, 386-7. Obligación de Martín Cortés, marqués del Valle, comprometiéndose a pagar a Juan de Lezcano 36.515 reales en el plazo de dos meses, Madrid, monasterio de San Francisco extramuros, 25 de marzo 1553. 
"así como heredó el mayorazgo, herede también la historia. En lo uno consiste la riqueza, y en lo otro la fama; de manera que andarán juntos honra y provecho. Mas, empero, esta herencia os obliga a seguir mucho lo que vuestro padre Fernando Cortés hizo, como a gastar bien lo que os dejó. No es menor loa ni virtud, ni quizá trabajo, guardar lo ganado, que ganar de nuevo, pues así se conserva la hacienda, que sostiene la honra". ${ }^{117}$

Otro de los acreedores de Martín Cortés era su sastre Juan Vicente Campel. ${ }^{118}$ Ya había tenido trato con Hernán Cortés, en cuyo testamento dispuso que se averiguasen las cuentas de los trabajos que realizó para su casa y cámara. ${ }^{119}$ Algunos habían sido abonados por Juan Galvarro antes de la muerte del conquistador, sin duda por la confección de varias prendas con las que Cortés pensaba "entregar" a su hija, tal como se estableció en el concierto matrimonial. ${ }^{120}$

Gómara también conocía y trataba a Juan Vicente, con el que coincidió en varias ocasiones en la corte, una de ellas en el pleito de los hermanos Aranda con el segundo marqués del Valle, ${ }^{121}$ y mantuvo tratos económicos. ${ }^{122}$ Por ello, dado que el sastre estuvo en Sevilla cuando Hernán Cortés esperaba a su hija, bien pudo ser otro de los informantes de Gómara sobre los preparativos del "ajuar" de María, aspecto que el cronista recordó con la expresión "con cien mil ducados y vestidos". ${ }^{23}$

\section{Balance de una relación}

Por los testimonios presentados no cabe duda que Francisco López de Gómara tuvo relación con Hernán Cortés y su hijo de vista, habla y conver-

117 López de Gómara, Historia de la conquista, p. 5.

118 AHPV, 139, fol. 871. Carta cuenta entre Diego Ferrer, en nombre de Martín Cortés, marqués del Valle, de los maravedís que debe a Juan Vicente, Valladolid, 27 de marzo de 1557. AHPV, 39, fol. 863. Poder en causa propia de Juan Vicente Campel a Martín Cortés, marqués del Valle, y a Diego Ferrer para que reciban y cobren las joyas empeñadas en seguridad de los maravedís que le debía el marqués, Valladolid, 13 de agosto de 1557.

119 Testamento de Hernán Cortés, Sevilla, 11 de diciembre de 1547 en Martínez (ed.), Documentos cortesianos, vol. 4, p. 333.

120 Muro, Hernando Cortés, p. 60.

121 ARChV, Pleitos Civiles, Moreno, Fenecidos, 2802-2. Declaración de Juan Vicente, sastre, en el pleito de los hermanos Aranda con los hijos y herederos de Hernán Cortés para el cobro de cierta cantidad que les adeudaba el marqués del Valle, Valladolid, 29 de agosto de 1551.

122 Lewis, "El testamento", p. 64.

123 López de Gómara, Historia de la conquista, CCLI, p. 336. 
sación pero de ninguna declaración es posible deducir, ni siquiera intuir, su actuación como capellán o cronista a sueldo, lo que corrobora que nunca lo fue. Es evidente que el conquistador le merecía gran estima pues en todo el tiempo que lo conoció lo tuvo "por muy buen caballero e amigo de guardar su palabra e muy buen cristiano, según que lo mostraba en las grandes y muchas limosnas y caridades que hacía", ${ }^{124}$ cualidades que también destacó al tratar de la "Condición de Cortés". ${ }^{125}$ Desconocemos hasta qué punto Hernán Cortés trató a Gómara, aspecto mejor conocido en el caso de su hijo, con el que el cronista declaró tener amistad y conversación. El segundo marqués no ocultó el afecto que le profesó pues Mauricio de la Cuadra, refiriéndose al clérigo, en 1558 escribió a Jerónimo Zurita: "Contóme el marqués del Valle ques mucho suyo". ${ }^{126}$

Por lo que afecta a su obra americanista lo más interesante, sin duda, es su declaración de que conoció a Cortés cuando regresó a España la primera vez — dato hasta la fecha ignorado- - y la confirmación de su relación con Andrés de Tapia, uno de sus confidentes. Hay que destacar también que Gómara trató a los criados y servidores de Hernán Cortés - Pedro de Ahumada, Diego Ferrer, Jaime Campos, etc. - con los que conversó y a través de los que tuvo acceso a sus papeles. Todos estos vínculos permiten una mejor interpretación de La conquista de México.

En los casos comentados, la presencia y declaraciones de Gómara son de gran interés para aclarar su relación, aparentemente distante, con Hernán Cortés y mucho más cercana con don Martín, el segundo marqués del Valle, además de para enriquecer la biografía y trayectoria de los tres personajes. En este sentido, las palabras de Gómara revelan aspectos desconocidos, rectifican algunas de las afirmaciones que tradicionalmente se han asumido sin discusión, matizan otras y, aunque nos gustaría que fuese de distinta manera, siguen suscitando preguntas hasta el momento sin respuestas concluyentes. Confiamos en que nuevos documentos puedan contribuir a saber más de su relación con los marqueses del Valle.

Recibido el 23 de septiembre de 2009

Aceptado el 11 de mayo de 2010

124 ARChV, Pleitos Civiles, Masas, Fenecidos, 3351-2. Probanza de los testamentarios de Hernán Cortés. Declaración de López de Gómara, Valladolid, 26 de enero de 1549.

125 López de Gómara, Historia de la conquista, CCLII, pp. 336-337.

126 Jiménez de la Espada, De un curioso percance, p. 9. 


\section{Bibliografía}

Miguel Ángel de Bunes Ibarra: "Cortés y los hermanos Barbarrojas, vidas paralelas en los escritos de Francisco López de Gómara", Revista de Indias, Vol. XLVII, n. ${ }^{\circ}$ 181, Madrid, septiembre-diciembre 1987, pp. 900-906.

Glen Carman: Rhetorical conquests: Cortés, Gómara, and Renaissance imperialism, West Lafayette, Indiana, Purdue University Press, 2006.

Bartolomé de las Casas: Historia de las Indias, Juan Pérez de Tudela Bueso (ed.), Madrid, Atlas, Biblioteca de Autores Españoles, 1961.

Antonio M. Cátedra: Nobleza y lectura en tiempos de Felipe II. La biblioteca de don Alonso Osorio, marqués de Astorga, Valladolid, Junta de Castilla y León, 2002.

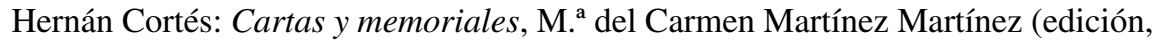
estudio y notas), Valladolid, Consejería de Cultura y Turismo / León, Universidad, 2003.

Mariano Cuesta Domingo: "Los cronistas oficiales de Indias. De López de Velasco a Céspedes del Castillo", Revista Complutense de Historia de América, n. ${ }^{\circ}$ 33, Madrid, 2007, 115-150.

Bernal Díaz del Castillo: Historia verdadera de la conquista de la Nueva España, Miguel León Portilla (ed.), Madrid, Historia 16, 1984.

El Códice de los trajes. Trachtenbuch / [Chistoph Weiditz; estudio histórico-científico de José Luis Casado Soto], Valencia, Grial, 2001.

Luis Fernández Martín: "Hernán Cortés y su familia en Valladolid (1542-1605)", en Hernán Cortés hombre de empresa, Valladolid, Casa-Museo de Colón y Seminario Americanista de la Universidad, 1990, pp. 309-349.

Manuel Foronda y Aguilera: Estancias y viajes del emperador Carlos V, desde el día de su nacimiento hasta el de su muerte, Madrid, Sucesores de Rivadeneyra, 1914.

Bernardo García Martínez: El marquesado del Valle. Tres siglos de régimen señorial en Nueva España, México, El Colegio de México / Centro de Estudios Históricos, 1969.

Jorge Gurría Lacroix: "Prólogo" a Francisco López de Gómara: Historia general de las Indias y vida de Hernán Cortés, Caracas, Biblioteca Ayacucho, 1979.

Ramón Iglesia: Cronistas e historiadores de la conquista de México; el ciclo de Hernán Cortés, México, El Colegio de México, 1942.

Nora Edith Jiménez: Francisco López de Gómara. Escribir historias en tiempos de Carlos V, Zamora, Michoacán, El Colegio de Michoacán / Instituto Nacional de Antropología e Historia, 2001.

Marcos Jiménez de la Espada: De un curioso percance que tuvo en Anvers el presbítero López de Gómara, Madrid, Imprenta Fontanet, s.a. [circa 1888]. 
Robert Earl Lewis: The humanistic historiography of Francisco López de Gómara (1511-1559), Ann Arbor, Michigan, University Microfilms International, 1987.

- "El testamento de Francisco López de Gómara y otros documentos tocantes a su vida y obra", Revista de Indias, Vol. XLIV, n. ${ }^{\circ} 173$, Madrid, enero-junio 1984, pp. 61-79.

Francisco López de Gómara: La istoria de las Yndias y conquista de Mexico, Çaragoça, en casa de Agustín Millán, 1552. Ejemplar R/12178 de la Biblioteca Nacional de España (Madrid).

- Primera y segunda parte de la Historia General de las Indias con todo el descubrimiento y cosas notables que han acaecido dende que se ganaron ata el año de 1551. Con la conquista de México y de la Nueva España. En Çaragoça, 1553. A costa de Miguel Çapila mercader de libros vecino de Çaragoça [En el colofón: En casa de Agustín Millán, y acabose víspera de la Navidad año de 1552], Ejemplar U/Bc I y R 323 de la Biblioteca Histórica de Santa Cruz de la Universidad de Valladolid y BR V/1150 de la Real Biblioteca, de Madrid.

- Annales del emperador Carlos Quinto. Biblioteca Nacional de España, Madrid. Ms. 1751, fs. 1-85v.

- Annals of the Emperor Charles the V, Roger Bigelow Merriman (ed.), Oxford, The Clarendon Press, 1912.

- Los corsarios Barbarroja, Madrid, Ediciones Polifemo, El Espejo Navegante, 1989.

- Historia de la conquista de México, estudio preliminar de Juan Miralles Ostos, México, Porrúa, 1997.

- Guerras de mar del emperador Carlos V [Compendio de lo que trata Francisco López en el libro que hizo de las guerras de mar de sus tiempo], Miguel Ángel de Bunes Ibarra y Nora Edith Jiménez (eds.), Madrid, Sociedad Estatal para la conmemoración de los centenarios de Felipe II y Carlos V, 2000.

Amada López de Meneses: "El primer regreso de Hernán Cortés a España”, Revista de Indias, Vol. XIV, n. ${ }^{\circ}$ 55-56, Madrid, enero-junio 1954, pp. 68-91.

José Luis Martínez: Hernán Cortés, Madrid, Fondo de Cultura Económica (FCE), 1992.

- (ed.): Documentos Cortesianos, 4 ts., México, Fondo de Cultura Económica (FCE ) / Universidad Nacional Autónoma de México (UNAM), 1990- 1994.

M. ${ }^{a}$ del Carmen Martínez Martínez (ed.): En el nombre del hijo. Cartas de Martín Cortés y Catalina Pizarro, México, UNAM / Instituto de Investigaciones Filológicas / Centro de Estudios Mayas, 2006.

Juan Miralles Ostos: "Estudio preliminar" a Francisco López de Gómara, Historia de la conquista de México, México, Porrúa, 1997. 
- Hernán Cortés: inventor de México, Barcelona, Tusquets, 2001.

- “Gómara, ¿Capellán de Cortés?”, Boletín de la Real Academia de la Historia, T. CCV-Cuaderno II, Madrid, mayo-agosto 2009, pp. 165-175.

Gabriel de Monterroso y Alvarado: Pratica civil y criminal \& instruction de escriuanos. [1565], Madrid, en casa de Pierres Cosin, 1579.

Valentín Moreno Gallego: "Letras misivas, letras humanas, letras divinas. La correspondencia del cardenal Granvela en la Real Biblioteca y sus cartas de autores", en Fernando Bouza (coord.): Cuadernos de Historia. Anejos. Cultura epistolar en la alta Edad Moderna. Uso de la carta y de la correspondencia entre el manuscrito y el impreso, Madrid, Universidad Complutense, Anejo IV, 2005, pp. 31-55.

Antonio Muro Orejón: Hernando Cortés. Exequias, almoneda e inventario de sus bienes, Sevilla, Escuela de Estudios Hispano-Americanos, 1966.

Enrique Otte: "Nueve cartas de Diego de Ordás", Historia Mexicana, T. XIV-1, México, julio-septiembre 1964, pp. 102-129.

José Pinilla: "López de Gómara en el Archivo de Protocolos de Madrid", Celtiberia, Revista del Centro de Estudios Sorianos, I, número 2, Soria, 1951, pp. 390-92.

Demetrio Ramos: Hernán Cortés. Mentalidad y propósitos, Madrid, Rialp, 1992.

Jesús Urrea: Arquitectura y nobleza. Casas y palacios de Valladolid, Valladolid, IV Centenario Ciudad de Valladolid, 1996.

Simón Valcárcel Martínez: "Una aproximación a Francisco López de Gómara", Caravelle. Cahiers du Monde Hispanique et Luso-Bresilien, n. ${ }^{\circ}$ 53, Toulouse,1989, pp. 7-24.

Germán Vázquez (ed.): La conquista de Tenochtitlan, Madrid, Historia 16, 1988. 